\title{
Some risk factors for hypertension in the United Arab Emirates
}

S. Sabri, ${ }^{1}$ A. Bener, ${ }^{2}$ V. Eapen, ${ }^{1}$ M.S.O. Abu Zeid, ${ }^{3}$ A.M. Al-Mazrouei ${ }^{4}$ and J. Singh ${ }^{5}$

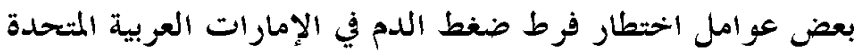

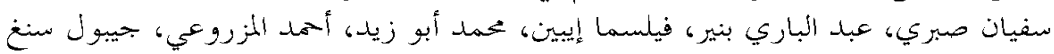

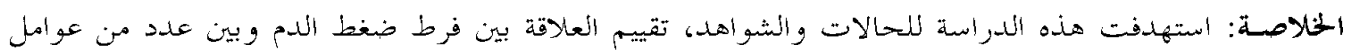

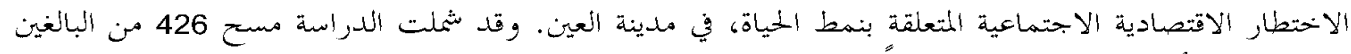

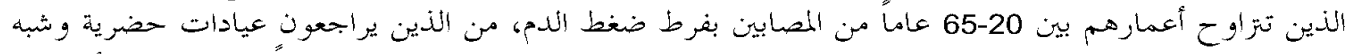

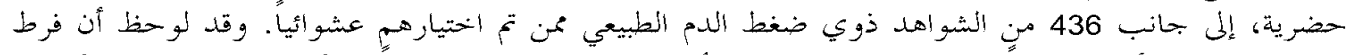

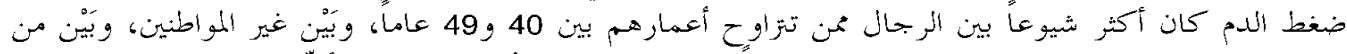

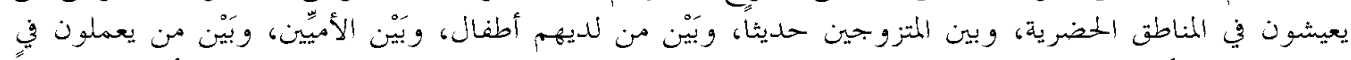

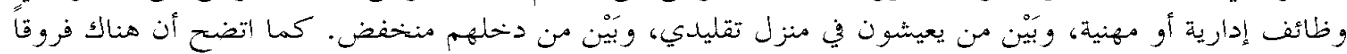

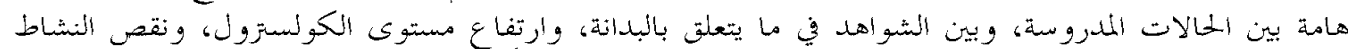

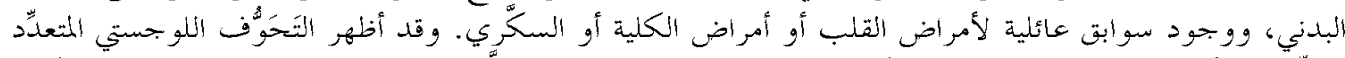

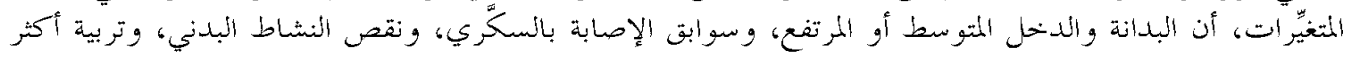

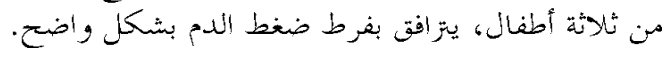

ABSTRACT A case-control study evaluated the relationship between hypertension and socioeconomic and lifestyle factors in Al-Ain city. The survey included 426 hypertensive adults aged 20-65 years attending urban and semi-urban clinics and a randomly selected sample of 436 normotensive controls. Hypertension among cases was higher for men, age 40-49 years, non-UAE nationals, urban living, currently married, having children, illiterate, administrative/professional job, living in traditional house and low income. There were significant differences between cases and controls with regard to obesity, raised cholesterol level, low physical activity and family history of heart disease, kidney disease or diabetes. Multivariate logistic regression analysis revealed that obesity, medium/high income, history of diabetes, low physical activity and having $3+$ children were significantly associated with hypertension.

\section{Certains facteurs de risque d'hypertension aux Émirats arabes unis}

RÉSUMÉ Une étude cas-témoins a évalué la relation entre l'hypertension et des facteurs socioéconomiques et liés au mode de vie dans la ville d'Al-Ain. L'étude comprenait 426 adultes hypertendus âgés de 20 à 65 ans qui consultaient dans des dispensaires urbains et semi-urbains et un échantillon, sélectionné de manière aléatoire, de 436 témoins normotendus. L'hypertension parmi les cas était plus élevée chez les hommes, âgés de 40 à 49 ans, non ressortissants des Émirats arabes unis, vivant en milieu urbain, mariés au moment de l'étude, ayant des enfants, analphabètes, occupant un emploi administratif/professionnel, vivant en maison traditionnelle et ayant un faible revenu. II y avait des différences significatives entre les cas et les témoins concernant l'obésité, un taux de cholestérol élevé, une activité physique faible et des antécédents familiaux de maladie cardiaque, de maladie rénale ou de diabète. L'analyse de régression logistique multivariée a révélé que l'obésité, un revenu moyen/élevé, des antécédents de diabète, une activité physique faible et le fait d'avoir plus de trois enfants étaient significativement associés à l'hypertension.

${ }^{1}$ Department of Psychiatry, Faculty of Medicine and Health Science, UAE University, United Arab Emirates. ${ }^{2}$ Department of Medical Statistics and Epidemiology, Hamad Medical Corporation and School of Epidemiology and Health Sciences, University of Manchester, United Kingdom.

${ }^{3}$ Primary Health Care Clinic, Oud Al Thoba, Ministry of Health, Al-Ain, United Arab Emirates.

${ }^{4} K$ halifa Hospital, Abu Dhabi Health Authority, Abu Dhabi, United Arab Emirates.

${ }^{5}$ Department of Biological Sciences, University of Central Lancashire, United Kingdom.

Received:22/06/03; accepted:23/12/03

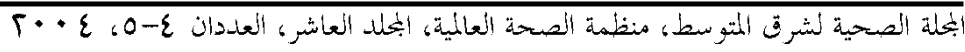




\section{Introduction}

The United Arab Emirates (UAE), like other developing countries, has undergone rapid changes during the past 2 decades [1]. The discovery of oil in the middle of the last century has contributed to significant social change, and UAE, along with other Gulf Arab states, have experienced a rapid transition in its socioeconomic status. People in UAE now enjoy a high standard of living and substantial improvements in their living conditions. There has been a dramatic rise in the national economy, expressed in terms of per capita income. In 2001, the gross domestic product (GDP) per capita were estimated as US\$ 22800 . The infant mortality rate has decreased from 10.5 per 1000 live births in 1981 to 6.6 in 2000 and life expectancy has increased from 68 years in 1977 to 75 years in 2000 (Ministry of Health, Annual Report, 1980-2000) [2].

Rapid economic growth in UAE has, however, brought about marked changes both in lifestyle and in patterns of health and disease. With the greater availability of housekeepers, cars, televisions and sophisticated household appliances, the lifestyle of the people of UAE has become more sedentary, and watching television and eating snack foods are the main leisure-time activities. Hypertension has become one of the leading public health problems.

Hypertension is a major contributor to atherosclerosis-induced cardiovascular disease $[3,4]$. The prevalence is higher in men than in women below the age of 35 years but by the age of 65 years the prevalence is higher in women [5]. In elderly women, it is the single most important risk factor for cardiovascular disease [6].

Data available from several Eastern Mediterranean countries indicate that hypertension is emerging as an important cause of morbidity and mortality. Epidemi- ological surveys on hypertension report a prevalence of $20 \%$ to $26 \%$ in the adult population [7]. In some urban areas high blood pressure may affect up to $30 \%$ of the adult population [8]. The prevalence of hypertension appears to be lower in rural than in urban areas [9-11]. Other risk factors, such as obesity, dyslipidaemia, diabetes and smoking, are also higher among hypertensive than normotensive people [12]. There is also a significant association between hypertension and diabetes mellitus in the UAE $[3,4,13]$.

There have been no systematic studies in the UAE population of the relationship between health and socioeconomic factors such as income or demographic factors including education and occupation. Since each community has its own common and unique socioeconomic determinants for cardiovascular diseases, particularly hypertension, it is important to study these variables in different populations. In the UAE it is believed that the effect of education and occupation on health are much weaker than in the Western European countries due to differences in the educational system and the influence of the industrial economy in Europe.

The present study in the city of Al-Ain, UAE, compared hypertensive patients attending primary health care clinics with non-hypertensive controls. The aim was to investigate the importance of socioeconomic status and lifestyle habits in relation to hypertension.

\section{Methods}

This was a matched case-control study to determine the relationship between hypertension and demographic, socioeconomic and lifestyle factors. The survey was conducted from October 2001 to July 2002.

لبحلة الصحية لشرق المثتوسط، منظمة الصحة العالمية، البحلد العاشر، العددان ع-0، ع • • 


\section{Sampling procedure}

A multi-stage stratified cluster sampling design was developed using the administrative divisions of the Al-Ain city medical health district which have approximately equal numbers of inhabitants. In order to secure a representative sample of the study population, sampling was stratified with proportional allocation according to stratum size from urban and semi-urban areas. The sample size was determined on the $a$ priori assumption that the prevalence of hypertension in the UAE would be more or less similar to the $20 \%$ rate observed in the pilot study. Assuming the prevalence of hypertension to be $20 \%$ and allowing for an error of $5 \%$ at the $1 \%$ level of significance (Type 1 error) a sample size of 500 cases and 500 matched controls would be required. Of the total 22 primary health care clinics in Al-Ain medical health district, 8 clinics were selected randomly (7 from urban and 1 from semi-urban areas).

\section{Selection of participants}

The study population was identified by recruiting consecutive hypertensive patients aged 20-65 years attending any of the clinics for follow-up examination or any other cause during a specified period of time. The researcher visited each clinic in a rotation of 2-3 weeks and reviewed the medical records of the first 20 hypertensive patients attending any of the specified primary health centres until the target sample was reached. The exclusion criteria were non-Arab national, any severe chronic disease, age less than 20 and more than 65 years.

To select the control group, for every hypertensive case a matching pair who was non-hypertensive and met the same inclusion criteria were recruited from the same clinic. The control group subjects were identified from the visitors escorting the patients to the health care centre or those attending for any other reason. Cases and controls were matched for age, sex and nationality. Before conducting the interview, the investigator reviewed the medical file of the controls (history and examination) to ensure they were suitable for the inclusion criteria of the research, in particular to check that they were free of any severe chronic diseases.

\section{Data collection}

Patients were checked by the general practitioner to see whether they met the inclusion criteria of the study and whether they had any family history of severe chronic diseases. The recruited patients were given a brief explanation about the study and were instructed to give their consent to participate in the study. They were asked by either the principal investigator or the nurse to fill out the questionnaire. Qualified nurses measured the blood pressure, height, and weight of the participants.

The survey was based on standardized interviews performed by trained health professionals and nurses. Informed consent was obtained from each person who agreed to enter the study. The participants were interviewed about their age, sex, nationality, educational level, occupation, place of living (urban or semi-urban), lifestyle habits, previous family history of hypertension, diabetes or kidney problems and current use of medication for hypertension and diabetes. Blood pressure was measured and height and weight were measured using standardized methods with participants wearing light clothes without shoes. Information on cholesterol level was collected from the patient's medical record.

Blood pressure measurement was carried out by practising nurses who were trained for 1 week on the use of the sphygmomanometer and how to measure blood 
pressure with patients in the sitting position. It was measured from the right upper arm, with a random zero sphygmomanometer with a $14 \mathrm{~cm}$ cuff, after the participants had rested for 10 minutes and was recorded to the nearest $\mathrm{mmHg}$. Systolic pressure was recorded at the appearance of sounds (first Korotkoff sounds) and diastolic pressure was recorded at the disappearance of sounds (fifth Korotkoff sounds). The mean value obtained from 3 readings was used in the analysis.

\section{Questionnaire}

The questionnaire and criteria for hypertension were designed to meet the objectives of this study. A translated Arabic version of the questionnaire was revised by the bilingual physician (M.S.O.A-Z) and translated back by a bilingual co-investigator, unacquainted with the original English version. Both translators met and made the necessary corrections, modifications and rewording after considering the minor differences and discrepancies that had occurred.

In a pilot study as a part of the process of validation, the first 20 patients were asked about the clarity and appropriateness of items on the questionnaire. Minor changes were made in the questionnaire taking into account their feedback.

In addition to the questionnaire, a review was made of the medical files of all participants recruited.

\section{Definitions}

Hypertension was defined according to World Health Organization (WHO) standardized criteria [14] as systolic BP $\geq 140$ $\mathrm{mmHg}$ and/or diastolic BP $\geq 90 \mathrm{mmHg}$ and/ or the use of antihypertensive medication [14]. Control participants were those with systolic blood pressure $<140 \mathrm{mmHg}$ or di- astolic $<90 \mathrm{mmHg}$ and not currently taking antihypertensive medication.

BMI was calculated as the weight in kilograms (1 kg subtracted to allow for clothing) divided by height squared in meters. Subjects were classified into 3 categories: acceptable weight (BMI < 25 kg/ $\mathrm{m}^{2}$ ); overweight (BMI 25-29.9 kg/m²); and obese (BMI 30+ kg/m²) [15].

Smoking behaviour was classified as: current smoker (regularly smoked at least 1 cigarette per day), ex-smoker (given up smoking for at least 6 months) and nonsmoker (never smoked regularly).

High cholesterol was a total cholesterol level > $230 \mathrm{mg} / \mathrm{dL}$, low-density lipoprotein (LDL) cholesterol level > $130 \mathrm{mg} / \mathrm{dL}$ or triglyceride level 200-400 mg/dL.

Alcohol consumption was defined as: never drank, current drinker or ex-drinker. No data were obtained on alcohol consumption among women because it is uncommon among females and due to the difficulty in gathering information on this subject in this conservative Muslim community.

Physical activity was classified as follows: sedentary and relatively inactive (not practising sports or practising $<1$ hour/ week); relatively active (practising sports for 1-3 hours a week); or highly active (practising sports for $>3$ hours a week).

Healthy eating was assessed by recording the number of times per week that fruit and vegetables were consumed.

\section{Analysis}

The data were analysed using SPSS, version 11. Student $t$-test was used to find the difference between means of systolic and diastolic blood pressure among hypertensive and non-hypertensive patients. MannWhitney test was used for non-parametric distribution. The chi-squared test was used

لبحلة الصحية لشرق المثتوسط، منظمة الصحة العلمية، البحلد العاشر، العدذان ع-0، ع • • 
for comparison of frequencies between hypertensive and non-hypertensive people and the frequency of other associated socioeconomic and lifestyle factors. Logistic regression analysis was used to adjust for potential confounders and to order the importance of risk factors (determinants) for hypertension. Logistic regression results were expressed as odds ratios (OR) and 95\% confidence interval (CI) along with $P$ values (derived from likelihood ratios statistics which have a chi-squared distribution). The level $P<0.05$ was the cut-off value for significance.

\section{Results}

Of the 500 patients with hypertension recruited, 64 did not participate in the study and thus 436 cases and 436 matched nonhypertensive controls were included in the final analysis (87.2\% response rate for completion of the study).

Among hypertensive patients, the mean and standard deviation (SD) of blood pressure [systolic 141.9 (17.1) mmHg/diastolic 92.7 (9.8) $\mathrm{mmHg}$ ] was significantly higher than for controls [systolic 116.8 (8.7) $\mathrm{mmHg}$ / diastolic 75.7 (6.2) $\mathrm{mmHg}](P<$ 0.0001).

Among the hypertensive patients, the categories with the highest rates of hypertension were: men (55.3\%), age group 4049 years (39.7\%), non-UAE nationals (52\%), urban living (93.3\%), currently married (86.7\%), having children (93.6\%), illiterate (33.7\%), administrative/professional job (40.7\%), living in mud-brick or traditional house $(56.9 \%)$ and low income (< 5000 dirhams per month) (34.1\%) (Table 1).

Table 1 compares the sociodemographic characteristics of hypertensive patients and normotensive controls. There were statistically significant differences between cases and controls in the percentage of participants having 3 or more children $(P=$ 0.034), administrative/professional occupation $(P<0.037)$, (low/medium income (5000-9999 dh) $(P<0.001)$ and obesity $\left(\mathrm{BMI}>30 \mathrm{~kg} / \mathrm{m}^{2}\right)(P<0.001)$.

Table 2 compares the lifestyle habits of cases and controls. Significantly more patients with hypertension than controls were current smokers $(P=0.047)$, consumed alcohol $(P<0.03)$ and had a low level of physical activity $(P=0.007)$.

Table 3 shows a comparison of the medical conditions of hypertensive patients and non-hypertensive control participants. Significantly more patients with hypertension than controls had raised cholesterol levels $(P<0.001)$ or a family history of heart disease $(P<0.001)$, kidney disease $(P<0.033)$ or diabetes $(P<0.001)$.

A stepwise logistic regression analysis was used to adjust for potential confounders and order the importance of risk factors (determinants) for hypertension status (0 for non-hypertensive and 1 hypertensive) (Table 4). The logistic regression model was adjusted for age, sex, nationality and marital status. As can be seen from this table, factors associated with hypertension were: obesity $\left(\mathrm{BMI}>30 \mathrm{~kg} / \mathrm{m}^{2}\right)(P<$ $0.0001)$, medium/high income $(5000+\mathrm{dh})$ $(P<0.001)$, family history of diabetes $(P<$ $0.001)$, no physical activity $(P=0.003)$ and a high number of children $(3+)(P=$ 0.026).

\section{Discussion}

Hypertension is the most common of the cardiovascular diseases and is one of the most powerful contributors to cardiovascular morbidity and mortality especially from strokes and congestive heart failure [16-18]. In the present study, hypertension was found to be associated with poor

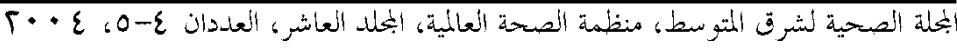




\begin{tabular}{|c|c|c|c|c|c|c|c|}
\hline \multicolumn{8}{|l|}{$\overline{\text { Eastern }}$} \\
\hline \multicolumn{8}{|c|}{$\begin{array}{l}\text { Table } 1 \text { Socioeconomic characteristics of clinic attenders with hypertension and non } \\
\text { hypertensive controls in Al-Ain city, United Arab Emirates (UAE) }\end{array}$} \\
\hline \multirow[t]{2}{*}{ Variable } & \multicolumn{2}{|c|}{$\begin{array}{c}\text { Cases } \\
(n=436)\end{array}$} & \multicolumn{2}{|c|}{$\begin{array}{l}\text { Controls } \\
(n=436)\end{array}$} & \multirow[t]{2}{*}{$\begin{array}{l}\text { Odds } \\
\text { ratio }\end{array}$} & \multirow[t]{2}{*}{$95 \% \mathrm{Cl}$} & \multirow[t]{2}{*}{ P-value } \\
\hline & No. & $\%$ & No. & $\%$ & & & \\
\hline \multicolumn{8}{|l|}{ Sex } \\
\hline Female & 195 & 44.7 & 217 & 50.2 & 1.00 & & \\
\hline Male & 241 & 55.3 & 219 & 49.8 & 0.903 & $0.79-1.03$ & 0.154 \\
\hline \multicolumn{8}{|l|}{ Age (years) } \\
\hline$<40$ & 98 & 22.4 & 134 & 31.1 & 1.00 & & \\
\hline $40-49$ & 173 & 39.7 & 172 & 39.9 & 0.73 & $0.51-1.03$ & 0.062 \\
\hline $50-59$ & 93 & 21.3 & 74 & 17.2 & 0.80 & $0.54-1.18$ & 0.239 \\
\hline $60+$ & 72 & 16.5 & 51 & 11.8 & 0.89 & $0.54-1.47$ & 0.628 \\
\hline \multicolumn{8}{|l|}{ Nationality } \\
\hline UAE & 209 & 48.0 & 207 & 47.7 & 1.00 & & \\
\hline Other Arab & 226 & 52.0 & 227 & 52.3 & 1.014 & $0.77-1.32$ & 0.946 \\
\hline \multicolumn{8}{|l|}{ Area } \\
\hline Urban & 402 & 93.3 & 375 & 86.4 & 1.00 & & \\
\hline Semi-urban & 29 & 6.7 & 59 & 13.6 & 1.30 & $0.87-1.87$ & 0.242 \\
\hline \multicolumn{8}{|l|}{ Marital status (current) } \\
\hline Married & 372 & 86.7 & 359 & 83.9 & 1.00 & & \\
\hline Single & 57 & 13.3 & 69 & 16.1 & 1.25 & $0.84-1.87$ & 0.242 \\
\hline \multicolumn{8}{|l|}{ No. of children } \\
\hline$<3$ & 101 & 23.3 & 123 & 29.1 & 1.00 & & \\
\hline $3+$ & 304 & 70.2 & 265 & 62.8 & 0.72 & $0.52-0.99$ & 0.034 \\
\hline Not married & 28 & 6.5 & 34 & 8.1 & 1.39 & $0.80-2.44$ & 0.216 \\
\hline \multicolumn{8}{|l|}{ Educational level } \\
\hline Illiterate & 145 & 33.7 & 126 & 29.2 & 1.00 & & \\
\hline Elementary/preparatory & 103 & 24.0 & 86 & 20.0 & 0.96 & $0.65-1.42$ & 0.833 \\
\hline Secondary & 44 & 10.2 & 40 & 9.3 & 1.09 & $0.63-1.88$ & 0.746 \\
\hline College/university & 138 & 32.1 & 179 & 41.5 & 1.43 & $0.86-2.38$ & 0.148 \\
\hline \multicolumn{8}{|l|}{ Occupation type } \\
\hline Not working & 50 & 11.6 & 45 & 10.3 & 1.00 & & \\
\hline \multicolumn{8}{|l|}{ Unskilled/semi-skilled } \\
\hline \multirow{2}{*}{\multicolumn{8}{|c|}{ Administrative/ }} \\
\hline & & & & & & & \\
\hline Housewife & 144 & 33.3 & 137 & 31.6 & 0.81 & $0.59-1.12$ & 0.188 \\
\hline \multicolumn{8}{|l|}{ Type of residence } \\
\hline Villa & 92 & 21.3 & 94 & 21.8 & 1.00 & & \\
\hline $\begin{array}{l}\text { Traditional mud-brick/ } \\
\text { prefabricated }\end{array}$ & 245 & 56.9 & 244 & 56.3 & 0.97 & $0.69-1.39$ & 0.882 \\
\hline Apartment & 94 & 21.8 & 95 & 21.9 & 1.01 & $0.72-1.44$ & 0.931 \\
\hline
\end{tabular}

البحلة الصحية لشرق المثتوسط، منظمة الصحة العالمية، المجلد العاشر، العددان ع-ه، ع • • 
Table 1 Socioeconomic characteristics of clinic attenders with hypertension and non-hypertensive controls in Al-Ain city, United Arab Emirates (UAE) (concluded)

\begin{tabular}{|c|c|c|c|c|c|c|c|}
\hline \multirow[t]{2}{*}{ Variable } & \multicolumn{2}{|c|}{$\begin{array}{c}\text { Cases } \\
(n=436)\end{array}$} & \multicolumn{2}{|c|}{$\begin{array}{l}\text { Controls } \\
(n=436)\end{array}$} & \multirow[t]{2}{*}{$\begin{array}{l}\text { Odds } \\
\text { ratio }\end{array}$} & \multirow[t]{2}{*}{$95 \% \mathrm{Cl}$} & \multirow[t]{2}{*}{ P-value } \\
\hline & No. & $\%$ & No. & $\%$ & & & \\
\hline \multicolumn{8}{|l|}{ Monthly income $(d h)^{\mathrm{a}}$} \\
\hline$<5000$ & 138 & 34.1 & 98 & 25.1 & 1.00 & & \\
\hline 5000-9999 & 140 & 34.6 & 176 & 45.1 & 1.77 & $1.24-2.53$ & $<0.001$ \\
\hline $10000-14999$ & 57 & 14.1 & 60 & 15.4 & 0.84 & $0.54-1.31$ & 0.413 \\
\hline $15000+$ & 80 & 17.3 & 56 & 14.4 & 0.66 & $0.39-1.13$ & 0.108 \\
\hline \multicolumn{8}{|l|}{$B M I\left(k g / m^{2}\right)$} \\
\hline Acceptable (<25) & 99 & 25.1 & 163 & 40.9 & 1.00 & & \\
\hline Overweight (25-29.9) & 132 & 33.5 & 150 & 37.6 & 0.69 & $0.48-0.99$ & 0.035 \\
\hline Obese $(30+)$ & 163 & 41.4 & 86 & 21.6 & 0.46 & $0.32-0.67$ & $<0.001$ \\
\hline
\end{tabular}

${ }^{a}$ US $\$ 1=3.68$ dirhams.

$\mathrm{n}=$ total number of participants (data were missing in some categories).

$\mathrm{Cl}=$ confidence interval.

$B M I=$ body mass index.

Table 2 Comparison lifestyle habits of clinic attenders with hypertension and nonhypertensive controls in Al-Ain city, United Arab Emirates

\begin{tabular}{|c|c|c|c|c|c|c|c|}
\hline \multirow[t]{2}{*}{ Variable } & \multicolumn{2}{|c|}{$\begin{array}{c}\text { Cases } \\
(n=436)\end{array}$} & \multicolumn{2}{|c|}{$\begin{array}{l}\text { Controls } \\
(n=436)\end{array}$} & \multirow[t]{2}{*}{$\begin{array}{l}\text { Odds } \\
\text { ratio }\end{array}$} & \multirow[t]{2}{*}{$95 \% \mathrm{Cl}$} & \multirow[t]{2}{*}{$P$-value } \\
\hline & No. & $\%$ & No. & $\%$ & & & \\
\hline \multicolumn{8}{|l|}{ Tobacco smoking } \\
\hline Never & 292 & 68.4 & 344 & 79.8 & 1.00 & & \\
\hline Current smoker & 55 & 12.9 & 42 & 9.7 & 0.65 & $0.41-1.02$ & 0.047 \\
\hline Ex-smoker & 80 & 18.7 & 45 & 10.4 & 0.74 & $0.41-1.31$ & 0.270 \\
\hline \multicolumn{8}{|l|}{ Alcohol consumption } \\
\hline Never & 402 & 94.1 & 413 & 97.2 & 1.00 & & \\
\hline Current/ex-drinker & 25 & 5.9 & 12 & 2.8 & 0.47 & $0.22-0.99$ & 0.030 \\
\hline \multicolumn{8}{|l|}{ Physical activity } \\
\hline$Y_{e s}^{a}$ & 188 & 43.1 & 229 & 52.5 & 1.00 & & \\
\hline No & 248 & 56.9 & 207 & 47.5 & 0.72 & $0.52-0.89$ & 0.007 \\
\hline \multicolumn{8}{|l|}{ Vegetable consumption } \\
\hline $3+$ times /week & 366 & 87.4 & 359 & 85.4 & 1.00 & & \\
\hline$<3$ times / week & 53 & 12.6 & 61 & 14.6 & 1.17 & $0.78-1.78$ & 0.428 \\
\hline \multicolumn{8}{|l|}{ Fruit consumption } \\
\hline $3+$ times /week & 341 & 81.6 & 342 & 81.8 & 1.00 & & \\
\hline$<3$ times /week & 77 & 18.4 & 76 & 18.2 & 0.98 & $0.68-1.42$ & 0.928 \\
\hline
\end{tabular}

$\mathrm{n}=$ total number of participants (data were missing in some categories).

$\mathrm{Cl}=$ confidence interval.

alf subject practised sport more than 1 hour per week.

بلملة الصحية لشرة المتو سط، منظمة الصحة العالمية، البحلد العاشر، العادان ع-0، ع • • 
Table 3 Comparison of medical condition of clinic attenders with hypertension and non-hypertensive controls in Al-Ain city, United Arab Emirates

\begin{tabular}{|c|c|c|c|c|c|c|c|}
\hline Variable & \multicolumn{2}{|c|}{$\begin{array}{c}\text { Cases } \\
(n=436)\end{array}$} & \multicolumn{2}{|c|}{$\begin{array}{l}\text { Controls } \\
(n=436)\end{array}$} & $\begin{array}{l}\text { Odds } \\
\text { ratio }\end{array}$ & $95 \% \mathrm{Cl}$ & P-value \\
\hline \multicolumn{8}{|l|}{ Cholesterol level } \\
\hline Normal & 149 & 34.6 & 128 & 29.5 & 1.00 & & \\
\hline Higher than normal & 140 & 32.5 & 12 & 2.8 & 0.10 & $0.05-0.19$ & $<0.001$ \\
\hline Not measured & 142 & 32.9 & 294 & 67.7 & - & - & \\
\hline \multicolumn{8}{|l|}{$\begin{array}{l}\text { Family history of } \\
\text { diabetes }\end{array}$} \\
\hline No & 345 & 80.4 & 399 & 93.7 & 1.00 & & \\
\hline Yes & 84 & 19.6 & 27 & 6.3 & 0.28 & $0.17-0.45$ & $<0.001$ \\
\hline \multicolumn{8}{|l|}{$\begin{array}{l}\text { Family history of heart } \\
\text { disease }\end{array}$} \\
\hline No & 352 & 82.1 & 415 & 98.1 & 1.00 & & \\
\hline Yes & 77 & 17.9 & 8 & 1.9 & 0.09 & $0.04-0.19$ & $<0.001$ \\
\hline \multicolumn{8}{|l|}{$\begin{array}{l}\text { Family history of kidney } \\
\text { problems }\end{array}$} \\
\hline No & 404 & 94.8 & 411 & 97.6 & 1.00 & & \\
\hline Yes & 22 & 5.2 & 10 & 2.4 & 0.45 & $0.19-1.00$ & 0.033 \\
\hline
\end{tabular}

$\mathrm{n}=$ total number of participants (data were missing in some categories).

$\mathrm{Cl}=$ confidence interval

\begin{tabular}{|c|c|c|c|}
\hline Independent variable & Odds ratio & $95 \% \mathrm{Cl}$ & $P$-value \\
\hline \multicolumn{4}{|l|}{$B M I$} \\
\hline$\left(<30 \mathrm{~kg} / \mathrm{m}^{2}=0,30+\mathrm{kg} / \mathrm{m}^{2}=1\right)$ & 4.29 & $2.76-6.66$ & 0.0001 \\
\hline Income ${ }^{a}$ & & & \\
\hline$(<5000 \mathrm{dh}=0,5000+\mathrm{dh}=1)$ & 2.69 & $1.76-4.10$ & 0.001 \\
\hline $\begin{array}{l}\text { Family history of diabetes } \\
\qquad(\mathrm{no}=0, \text { yes }=1)\end{array}$ & 2.58 & $1.69-3.74$ & 0.001 \\
\hline $\begin{array}{l}\text { Physical activity } \\
\qquad(\text { yes }=0, \text { no }=1)\end{array}$ & 1.80 & $1.20-3.69$ & 0.003 \\
\hline $\begin{array}{l}\text { No. of children } \\
\qquad(<3=0,3+=1)\end{array}$ & 1.67 & $1.23-2.11$ & 0.026 \\
\hline
\end{tabular}

البحلة الصحية لشرق المتوسط، منظمة الصحة العالمية، البحلد العاشر، العددان ع-0، ع • • 
health status as indicated by raised cholesterol levels and a family history of heart disease, renal disease or diabetes.

The present study confirms the hypothesis of an association between hypertension and poorer socioeconomic factors and more sedentary lifestyle. We found a positive association between hypertension and physical inactivity, smoking and obesity. These finding are similar to those of Johansson and colleagues in a study carried out in Sweden [19]. This has implications for preventive strategies, because smoking behaviour, body fatness and physical activity have been shown to be major candidates for possible early interventions [20].

Perhaps the common link to hypertension for all these sociodemographic factors is physical inactivity. If this were the case, it would suggest a number of potentially modifiable factors that could be targeted for intervention. A study in Finland has shown that the mean intensity of leisure time physical activity had a positive dose- response relationship with level of education and income [21]. It was also shown that married or engaged men, those less educated, on lower incomes and unemployed or retired had a shorter duration of conditioning physical activity especially in urban areas than others [21]. The authors of the study concluded that physical activity protects against poor health irrespective of high BMI and smoking.

Our finding that more expatriates than UAE nationals had hypertension is in keeping with previous findings of a Swedish study [22], which found that foreign-born individuals had a higher risk for poor health than Swedes after adjustment for sociodemographic and lifestyle factors.

In conclusion, the present study supports the importance of socioeconomic factors, lifestyle habits and family history in shaping risk for hypertension in UAE and indicates a need for more effective prevention programmes for control of hypertension in this fast developing Arab country.

\section{References}

1. Bener A, Gomes J, Hamouda MFB. Hypertension among workers occupationally exposed to hydrocarbons and organic solvents. Journal of environmental science and health, Part- $A, 1996$, 31:291-303.

2. Annual report. Preventive medicine in 20 years. Abu Dhabi, United Arab Emirates, Ministry of Health, 2000:1-270.

3. Bener A et al. Acanthosis nigricans, hyperinsulinaemia and risk factors for cardiovascular disease. Eastern Mediterranean health journal, 2000, 6:41624.

4. Corrao JM et al. Coronary heart disease risk factors in women. Cardiology, 1990, 77(suppl. 2):8-24.
5. Rowland M, Roberts J. Blood pressure levels and hypertension in persons aged 6-74 years: United States, 19761980. National Health and Nutrition Examination Survey 1. Hyattsville, Maryland, US Department of Health and Human Services, 1982.

6. Sarraf-Zadegan $\mathrm{N}$ et al. Prevalence of hypertension and associated risk factors in Isfahan, Islamic Republic of Iran. Eastern Mediterranean health journal, 1999, 5:992-1001.

7. Alwan A. Prevention and management of hypertension. Alexandria, World Health Organization, Regional Office for the Eastern Mediterranean, 1996 (WHO EMRO Technical Publication, No. 23).

بلملة الصحية لشرة المتو سط، منظمة الصحة العالمية، البحلد العاشر، العلددان ع-0، ع • • 
8. Alwan A. Prevention and control of cardiovascular diseases. Alexandria, World Health Organization, Regional Office for the Eastern Mediterranean, 1995 (WHO EMRO Technical Publication, No. 22).

9. Sarraf-Zadegan N, Amini-Nik S. Blood pressure pattern in urban and rural areas in Isfahan, Iran. Journal of human hypertension, 1997,11:425-8.

10. Sayeed MA et al. Prevalence of hypertension in Bangladesh: effect of socioeconomic risk factor on difference between rural and urban community. Bangladesh Medical Research Council bulletin, 2002, 28:7-18.

11. Faruqui A. Heart disease in South Asia: experiences in Pakistan. In: Hurst JW, ed. Clinical essays on the heart. Volume 2. New York, McGraw-Hill, 1983.

12. Laurenzi $M$ et al. Multiple risk factors in hypertension: results from the Gubbio study. Journal of hypertension, supplement, 1990, 8:S7-12.

13. Bener A et al. Association between blood levels of lead blood pressure and risk of diabetes and heart disease in workers. International archives of occupational and environmental health, 2001, 74(5):375-8.

14. World Health Organization/International Society of Hypertension. Guidelines for the management of hypertension. Journal of hypertension, 1999, 17:151-82.

15. Bray GA. Definition, measurement and classification of the syndrome of obesity. International journal of obesity, 1978, 2:99-112.

16. Kannel WB, Thom TJ. Declining cardiovascular mortality. Circulation, 1984, 70:331-6.
17. MacMahon $S$ et al. Blood pressure, stroke and coronary heart disease. Part 1 , Prolonged differences in blood pressure: prospective observational studies corrected for the regression dilution bias. Lancet, 1990, 335:765-74.

18. National Center for Health Statistics. Annual summary of births, marriages, divorces and deaths, United States, 1989. Monthly vital statistics report, 1990:38(13).

19. Johansson SE, Sundquist J. Change in lifestyle factors and their influence on health status and all-cause mortality. International journal of epidemiology, 1999, 28(6):1073-80.

20. Twisk JW, Kemper HC, van Mechelen W. Tracking of activity and fitness and the relationship with cardiovascular disease risk factors. Medicine and science in sports and exercise, 2000, 32(8):145561.

21. Lakka TA, Kauhanen J, Salonen JT. Conditioning leisure time physical activity and cardiorespiratory fitness in sociodemographic groups of middle-ages men in eastern Finland. International journal of epidemiology, 1996, 25(1): 86-93.

22. Sundquist J. Living conditions and health. A population-based study of labour migrants and Latin American refugees in Sweden and those who were repatriated. Scandinavian journal of primary health care, supplement, 1995, 13(2):128-34.

بلملة ألصحية لشرق المثتوسط، منظمة الصحة العالمية، البحلد العاشر، العلدان ع-0، ع + • 